\title{
A particularidade em cena: o lugar da atriz/ dramaturga no teatro
} The particularity on scene: the place of actress / dramaturg in the theater

Júnia Cristina Pereira ${ }^{1}$ 


\section{Resumo}

O presente trabalho busca discutir como se constituem as relações entre dramaturgia, autor(a) e cena, buscando traçar relações entre a visibilidade do lugar de enunciação e a emergência da autoria feminina, em especial no contexto de criações coletivas/colaborativas. Nessa esteira, e a partir do lugar de enunciação da autora, busca levantar questões sobre como são constituídas e atribuídas às obras as noções de "universal" e de "clássico", em oposição à noção de particularidade com que predominantemente tem sido recepcionada a produção coletiva/ colaborativa e feminina.

Palavras-chave: Autoria; lugar de enunciação; dramaturgia feminina; criação coletiva/colaborativa

\section{Abstract}

The present work seeks to discuss how the relationships between dramaturgy, author, and scene are constructed, seeking to trace relationships between the visibility of the place of enunciation and the emergence of female authorship, especially in the context of collective/collaborative creations. In this wake, and from the place of enunciation of the author, it tries to raise questions about how the notions of "universal" and "classical" are constituted and attributed to the works, as opposed to the notion of particularity with which the collective/collaborative and feminine production has been predominantly received.

Keywords: Authorship; place of enunciation; female dramaturgy; collective/ collaborative creation

ISSN: 1414.5731

E-ISSN: 2358.6958 


\section{O teatro masculino europeu que excetua as tradições populares}

Historicamente, as relações entre texto e cena se modificam, e a partir dessas modificações, também se altera a configuração do trabalho do(a) ${ }^{2}$ dramaturgo(a) ou escritor(a) de peças. Grosso modo, até o advento do encenador moderno (fim do século XIX), o dramaturgo protagonizava a autoria da criação teatral europeia, enquanto o encenador era visto como um agente secundário do fenômeno. Entretanto, apesar desse grande protagonismo do trabalho do dramaturgo, este não era visível na obra. Considerando a conceituação de Szondi (2001, p. 30) acerca do drama clássico, o dramaturgo

está ausente no drama. Ele não fala; ele institui a conversação. O drama não é escrito, mas posto. As palavras pronunciadas no drama são todas elas de-cisões [Ent-schlüsse]; são pronunciadas a partir da situação e persistem nela; de forma alguma devem ser concebidas como provenientes do autor. O drama pertence ao autor só como um todo, e essa relação não é parte essencial de seu caráter de obra.

Apesar de estar descrevendo um conceito em sua forma "pura" e não a realidade de obras específicas, o que Szondi teoriza é um dramaturgo em cuja obra as personagens agem segundo as leis próprias de sua dialética intersubjetiva, de forma que o ponto de vista do autor torna-se invisível. Sem lugar de enunciação aparente, é como se a fábula tivesse vida própria - um "animal aristotélico" - e só pudesse ter aquele desenvolvimento, não importando o desejo do autor. Assim, o autor torna-se tão mais transparente quanto mais dramática a sua obra for considerada. Para falar sobre esse dramaturgo transparente, ouso afirmar que não cabe o uso de uma linguagem inclusiva: ele é, efetivamente, um homem, e um homem europeu.

Marcar o gênero masculino invisibilizado desse dramaturgo clássico se faz importante, e não apenas por motivos históricos, mas também epistemológicos. De forma geral, dramaturgas não foram muito frequentes até o final do século XIX, porém esse não é exatamente o nosso ponto: aventamos que esta forma clássica do drama não comportaria um outro sujeito que não fosse o masculino. Trata-se de um aparente paradoxo, pois vimos que o lugar de enunciação do autor não estava em pauta. Vejamos: se aceitarmos a proposição de Simone de Beauvoir (1970), da mulher como o "outro", ela jamais poderia estar de forma transparente numa enunciação dramatúrgica. Como modelo teórico, sustentamos que uma enunciação transparente só é possível se for masculina, pois ela não tem a necessidade de tornar visível se quem enuncia é "um" ou "outro", será sempre o "um", ou o sujeito masculino. Dessa maneira, se o dramaturgo não está visível, é porque ele, homem, se torna portador de uma voz universal, e esse processo se torna, assim como ele próprio, invisível.

Além de se constituir como homem, nosso olhar demarca o dramaturgo clássico também como europeu, pois ele só pode ser concebido numa análise que exclui manifestações espetaculares de outros continentes e centra suas investigações na Europa, excluindo também, dela, as tradições populares, nas quais não existe contexto não somente para a forma dramática pura, mas também para a primazia do texto e/ou do autor.

\footnotetext{
${ }^{2}$ Apesar do efeito de quebra de fluência, faremos uso da linguagem inclusiva, variando propositalmente entre a forma masculina (com a feminina entre parênteses) e a forma feminina (com a masculina entre parênteses). Quando utilizarmos apenas a forma masculina ou a feminina, estaremos nos referindo em específico a experiências masculinas ou femininas.
} 
Sabemos que, a partir do fim do século XIX, o deslocamento do status do texto e a valorização da encenação irão retirar o dramaturgo do centro desse conceito de teatro, revisto por nós como "teatro masculino europeu que excetua as tradições populares". Assim, a obra do dramaturgo perderá em importância para o trabalho do encenador, que assumirá então o protagonismo do fazer teatral.

\section{O encenador moderno e a visibilidade da enunciação dramatúrgica}

Em seu verbete "Texto e Cena", Pavis (2005, p.406-408) apresenta duas possibilidades de relação dialética entre esses dois discursos: dramaturgia e encenação. Na primeira, há a concepção de que o texto apresenta uma potencialidade cênica que deve ser revelada pela encenação. Em outras palavras, toda obra dramatúrgica guardaria em si uma encenação latente, que precisa ser trazida à tona pelo encenador. Uma segunda possibilidade de relação entre texto e cena já parte da constatação da existência de uma defasagem e de uma separação entre o texto e a encenação, constituindo esta última como uma nova maneira de ler ou interpretar o texto. Esta segunda possibilidade parece ter enfatizado a dinâmica desse período histórico final do século XIX e início do século XX - no qual, com o surgimento da encenação moderna, o encenador ganhou maior relevância, uma vez que a originalidade das encenações passou a ser valorizada.

No Brasil, como marca de nosso colonialismo, nossa cena teatral vem se construindo tendo como referência a cena europeia. Assim, o teatro moderno brasileiro irá incorporar esse novo status do encenador europeu, inclusive "importando" diretores para a nossa cena, especialmente italianos. De acordo com Tania Brandão, o teatro moderno brasileiro surgiu como uma nova forma de fazer teatro, "em que um projeto artístico passava a ser o ponto de partida para a formulação de uma proposta, daí a importância que passou a ter o diretor, visto como o artista capaz de oferecer a constituição de um conceito de obra" (Brandão, 2013, p.91).

No final da década de 1950 e início da década de 1960, tanto a dramaturgia quanto a encenação desse teatro moderno brasileiro passaram a ser criticadas pelas marcas que traziam de sua maior fonte de inspiração: o que chamamos aqui de "teatro masculino europeu que excetua as tradições populares". A cena brasileira começou a ser vista como reprodutora dessa enunciação europeia, característica sobretudo do TBC - Teatro Brasileiro de Comédia. Essa crítica fazia parte de um contexto em que novos dramaturgos e encenadores buscavam a construção de uma dramaturgia e uma encenação nacionais. Ao mesmo tempo, ainda perdurava a ideia de que os textos europeus clássicos eram "universais", o que rendeu, da parte do encenador Augusto Boal, uma interessante abordagem no período escrito por ele como "nacionalização dos clássicos" no Teatro de Arena (1962-1964).

A abordagem do Teatro de Arena é original nesse período pois ela desvela o lugar europeu de enunciação dessas obras - O Melhor Juiz, o Rei, de Lope de Vega; O Tartufo, de Molière; e O Inspetor Geral, de Gogol. De forma paradoxal, Boal acredita na universalidade desses textos, porém consegue identificar elementos específicos de sua enunciação. Na visão dele, esses elementos específicos podem ser substituídos por elementos locais (ou nacionalizados) sem que haja prejuízo para o 
caráter universal da obra. Mais ainda, a permanência da atualidade da obra, após esse processo de "nacionalização", seria mesmo uma medida para determinar sua universalidade: "um clássico só é universal na medida em que for brasileiro. Não existe o 'clássico universal' que só o Old Vic ou a Comédie podem reproduzir. Nós também somos universais" (Boal, 1991, p.194).

Consideramos a abordagem de Boal em relação aos clássicos, apesar de ambígua, bastante inspiradora para o pensamento feminista, pois ao reconhecer marcas de nacionalidade - e, embora não seja muito explícito em sua teorização, sabemos que para Boal interessava sobretudo também as marcas de classe social - nos textos clássicos, abre-se a possibilidade de visibilizar essas marcas também em relação a gênero e raça. Conforme ficará claro no decorrer desse trabalho, consideramos aqui como uma importante referência de pensamento feminista a teoria do lugar de fala (Ribeiro, 2017), que busca questionar a universalidade e romper com o regime de autorização discursiva. Nesse sentido, a abordagem de Boal pode ser considerada inspiradora na medida em que ele visibiliza a nacionalidade de textos considerados universais.

Porém, de forma contraditória, Boal não nega a universalidade dos textos, mas propõe uma solução conciliadora: ele acredita que tais textos sejam universais e que seja possível não somente conservar essa universalidade como também habitá-la a partir de diferentes marcadores ou lugares de enunciação.

Nesse sentido, ao afirmar "Nós também somos universais", Boal ancora essa afirmação no fato de que podemos reler/reinterpretar as dramaturgias clássicas, mas não necessariamente produzi-las. Vista na perspectiva contemporânea, esta proposição nos inspira a perguntar: existiriam mesmo obras universais ou esse reconhecimento de Boal em relação a essas obras faz sentido apenas no contexto em que a popularização das mesmas e seu prestígio consolidado - muitas vezes por um processo de educação etnocêntrica e colonialista - atribuiu, de forma arbitrária, a um conjunto de obras uma certa "validação", oportuna para o Teatro de Arena naquele período? Qual o interesse em "nacionalizar" uma obra clássica, podendo-se construir uma obra nacional - e, por que não, clássica? Tais questionamentos fazem parte do pano de fundo de nossa investigação, que interroga a suposta universalidade atribuída a determinadas enunciações dramatúrgicas - e a outras não.

Em consonância com Calvino (1993), entendemos uma obra clássica como uma obra inesgotável, cujo conhecimento crítico nunca será exaustivo, uma obra "que nunca terminou de dizer o que tinha para dizer", que traz a memória e os ecos de todas as suas leituras e releituras históricas, mas se atualiza sempre no presente, uma obra que possui "um lugar próprio numa continuidade cultural" (Calvino, 1993, p.14). Ora, parece-me que a definição de Calvino é sobretudo externa à obra, e se relaciona muito mais ao contexto da recepção e da valorização social da obra do que propriamente aos seus fundamentos poéticos. A mitificação das obras clássicas quer ligar aspectos externos a aspectos internos da obra, e fazer parecer que a inserção de uma obra nessa rede de releituras e apropriações se dá a partir da excelência de suas qualidades internas, porém ousamos aventar que, para a atribuição do status de obra clássica ou universal, concorre de forma determinante o contexto social de sua produção.

Sabemos por exemplo, que Shakespeare possuía um bom relacionamento com o poder real de Elizabeth I. Sem questionar o valor artístico de sua obra, podemos 
supor que sua posição social tenha concorrido para a atribuição e consolidação do status de universal e de clássica à sua produção. Por outro lado, no âmbito nacional, sabemos que em geral a rica produção dramatúrgica realizada por mulheres no Brasil entre fins de 1960 e 1980 - entre elas, dramaturgas como Renata Pallottini, Hilda Hilst, Leilah Assumpção, Consuelo de Castro, Isabel Câmara e Maria Adelaide Amaral - não tem merecido releituras cênicas e críticas, tais como merecem até hoje as obras de Nelson Rodrigues e Plínio Marcos. De acordo com Vincenzo (1992), esse teatro produzido por mulheres entre 1960 e 1980, de forma inédita no Brasil, logrou realizar uma ampla leitura social e política da sociedade brasileira:

[...] a dramaturgia feminina surge e se afirma como um fenômeno de dupla face: como reflexão crítica sobre a modernização do país - na qual no entanto encontra sua própria possibilidade - mas ao mesmo tempo como reflexão sobre o corte e o consequente refluxo do projeto socializante. Na posição da mulher, figura submetida num mundo submetido, ficam mais evidentes os desdobramentos da dominação e mais evidentes os limites e contradições do próprio projeto revolucionário. Uma vez gorado este e em processo de refluxo, as situações da mulher oferecem matéria histórica e dramática "ótima" para o exame desses limites e contradições... [...] uma dramaturgia na intersecção da história individual (no caso, quase sempre, da mulher) com a História política e social. (Vincenzo, 1992, p.295)

Apesar da análise de Vincenzo considerar a originalidade e a relevância estética e sociopolítica da produção dramatúrgica desse conjunto de mulheres, observamos que, quiçá devido ao gênero feminino das dramaturgas no contexto de uma sociedade machista, tais obras permaneceram apartadas do status de "clássicas" ou "universais". Ora, isso talvez explique o fato de que essas dramaturgas, ainda de acordo com Vincenzo, não se auto intitulam "feministas": haveria, nessa rejeição ao termo, um desejo, ainda que não realizado, de não se prender a um nicho específico, podendo, supostamente, pertencer à categoria "universal". Porém, verificamos que tais dramaturgias não tiveram "passabilidade" na categoria de universal, e contra o desejo das autoras são até hoje consideradas como pertencentes ao nicho "dramaturgia de mulheres".

\section{A dramaturgia épica e a visibilidade da enunciação dramatúrgica}

Voltando à nossa "história do teatro masculino europeu que excetua as tradições populares", vemos que além da valorização da encenação, outro deslocamento da obra dramatúrgica no final do século XIX se deu com a chamada crise do drama clássico, e a emergência de características dos gêneros lírico e épico nas obras. Ora, no teatro épico, torna-se impossível obliterar a enunciação do dramaturgo, esta chega mesmo a ser sublinhada. Como exemplo extremo, temos a peça Um homem é um homem, de Bertolt Brecht, na qual, após a transformação do estivador Galy Gay em soldado, a personagem Leokadja Begbick se dirige ao público:

O senhor Bertolt Brecht afirma: um homem é um homem.

E isso qualquer um pode afirmar.

Porém o senhor Bertolt Brecht consegue também provar

Que qualquer um pode fazer com um homem o que desejar. (Brecht, 1987, p.182) 
Por maiores que sejam a popularização e o reconhecimento mundiais da obra de Brecht, é impossível esquecer por muito tempo o caráter específico de sua enunciação, devido à insistência com que o próprio autor sublinha sua autoria. $O$ apelo à teatralidade, característico do teatro épico, deixa explícito que tudo no teatro foi preparado, pensado, ensaiado, escolhido: pelo autor, pelo encenador, pelos(as) atores (atrizes). Em Um homem é um homem, temos um exemplo extremo da visibilização do autor, que se dá no próprio texto dramatúrgico. A partir da fala da personagem Begbick, a peça se revela como uma tese de Brecht. Supomos que a partir do momento em que uma peça pode ser a proposição de um homem alemão, se torna passível de ser também a proposição de uma mulher brasileira. No momento histórico em que os marcadores da enunciação são evidenciados no "teatro masculino europeu que excetua as tradições populares", torna-se visível o lugar de enunciação do dramaturgo, e a possibilidade teórica de existência de uma dramaturga torna-se real, ainda que permaneça a contradição, já apontada, na forma como essas diferentes obras são recepcionadas como "universais" ou "particulares".

Bem, não se trata aqui de creditar a Brecht a possibilidade de existência de dramaturgas no teatro, quando sabemos que em todas as áreas do conhecimento o reconhecimento da produção intelectual feminina tem sido uma conquista histórica das mulheres e, ao que nos consta, Brecht não é conhecido por estabelecer relações de gênero igualitárias com suas colaboradoras. Em verdade, dramaturgas sempre existiram, para além da história oficial do que chamamos "teatro masculino europeu que excetua as tradições populares". Se partimos do pressuposto de que a prática teatral não tem como fonte única os rituais gregos, mas antes nasce, em todas as culturas, da mitologia, da contação de histórias, das práticas rituais, comunitárias e recreativas das comunidades, sabemos que em diversas culturas as mulheres têm e tiveram papel preponderante nessas práticas e na transmissão do conhecimento oral de suas comunidades. Porém, na medida em que Brecht, em seu espaço/tempo histórico, assume a não neutralidade de seu discurso, acreditamos que ele abre caminho para que outras(os) sujeitas(os), situadas(os) fora da posição de privilégio discursivo em que Brecht se encontrava no "teatro masculino europeu..." possam, no futuro, ser ouvidos(as) de seus lugares considerados específicos.

\section{O status da dramaturgia coletiva/colaborativa}

Com efeito, a epicização da cena, a visibilidade da enunciação do dramaturgo e do encenador no teatro brasileiro desembocaram em uma busca dos grupos de atores e atrizes por protagonismo. Nossa suposição é de que existe uma relação entre a visibilidade dos lugares de enunciação da cena e a democratização desta enunciação: uma vez que a peça passa a ser vista como "apenas" o resultado da visão de mundo de alguém, ou de pelo menos duas pessoas (dramaturgo e encenador), nada mais lógico então que outras pessoas envolvidas nessa produção - os grupos de atores e atrizes - passem a reivindicar (no Brasil, mais sensivelmente a partir da década de 1970) a construção teatral a partir de sua própria visão de mundo. Como afirma o ditado popular: "Onde passa um boi, passa uma boiada". 
Nesse contexto das criações coletivas e colaborativas, o status do(a) dramaturgo(a) brasileiro(a) sofre um grande rebaixamento. Já quase não reconhecemos seu parentesco com o autor genial do século XIX, produzindo de forma isolada em sua "torre de marfim". A partir da emergência dos processos coletivos e colaborativos, o(a) dramaturgo(a) ou é apenas descartada(o) em prol da emergência de um coletivo de autoras(es) - atrizes(atores) - criadoras(es), ou se vê obrigada(o) a "descer" para a sala de ensaio, e se tornar mais um(a) criador(a) entre outros(as) criadores(as).

Verificamos, entretanto, com muita curiosidade, que, apesar dessa grande mudança no status da(o) dramaturga(o) - agora, sim, passível de ser descrito em linguagem inclusiva - , o mito da dramaturgia "clássica" ou "universal" permaneceu intocado e inatingível, como um fantasma a assombrar uma cena que se construiu como o seu avesso. No contexto dos processos coletivos e colaborativos, a ênfase não foi dada à universalidade das obras produzidas, que foram interpretadas, na maior parte das vezes, como obras autorais e ligadas à personalidade de seus(suas) criadores(as), cuja maior qualidade residia na emergência e valorização de vozes particulares, localizadas e identitárias, advindas muitas vezes da experiência pessoal da(o)(s) artista(s). Como ilustração dessa tendência, trago uma fala de Regina Casé, acerca do trabalho do Grupo Asdrúbal Trouxe o Trombone, um dos primeiros a trabaIhar com processos de criação coletiva no Brasil:

\footnotetext{
Então, tudo o que a gente produz é de todo mundo. O dinheiro veio de todo mundo, o trabalho, o investimento em tempo. Então são atores, pessoas que fazem teatro, que fizeram essa peça $\mathrm{O}$ Inspetor Geral do Gogol, depois fizeram Ubu, do Jarry, e agora tá fazendo essa - o Trate-me Leão, que é uma peça sobre a gente, sobre a vida da gente, parecida com a gente, escrita pela gente - mais pelo Hamilton, e isso é que é um grupo de teatro, é você querer uma maneira diferente de produzir isso, de viver isso, de viver a sua vida, e a sua produção ser de uma maneira diferente. Por isso que a gente é um grupo e não um ator trabalhando num elenco qualquer. Por isso que a gente é o Asdrúbal. (Casé, 1978)
}

É interessante como Casé não sente necessidade de dar explicações sobre a temática de $O$ Inspetor Geral e de Ubu, ela diz o nome dos autores - homens europeus - e isso basta. Ao falar, porém, de Trate-me Leão, frisa de forma insistente que a peça é "sobre a gente", referindo-se ao grupo "Asdrúbal Trouxe o Trombone". Ao que tudo indica, a produção coletiva/colaborativa se justifica, muitas vezes, por se ancorar na subjetividade das(os) artistas. Ora, a pergunta que nos fazemos é: trata-se apenas de uma característica ou é a expressão de uma delimitação ou fronteira que não pode ser ultrapassada e que separa, no campo da recepção teatral e no contexto das relações comerciais que a constituem, o "particular" do "universal"?

A partir de uma análise da produção dramatúrgica protagonizada por atrizes (atores) em contextos de criação coletiva/colaborativa, podemos afirmar que o princípio da inesgotabilidade das obras clássicas (Calvino) em geral não tem sido associado a esses trabalhos. Por exemplo, apesar de seu grande sucesso e importância histórica, não se tem notícia de uma montagem de Trate-me Leão posterior à do grupo Asdrúbal, como em geral de dramaturgias produzidas de forma coletiva/colaborativa. Grosso modo, podemos afirmar que essas dramaturgias são consideradas como a expressão daquele grupo naquele momento, e a simples ideia de uma releitura parece estranha 
ao nosso pensamento teatral. Atrizes e atores parecem assim acessar a produção dramatúrgica a partir de um lugar ambíguo, pois ao mesmo tempo em que encontram um espaço para expressão de suas subjetividades, tal espaço permanece apartado do status de "universal" e de "clássico", que as(os) assombra como um velho paradigma inacessível e que, apesar de velho, ainda é simbolicamente poderoso, podendo agregar valor ou mesmo ancorar a justificativa de montagem de um espetáculo.

\section{O lugar das atrizes/dramaturgas/dramaturgistas}

Buscamos descrever até aqui esse momento do teatro brasileiro a partir do qual atores (atrizes), passaram a ter acesso, pela sala de ensaio, ao processo de criação dramatúrgica. Chamamos a atenção para o fato de que esse lugar de enunciação de forma geral tem se construído como um lugar de fala identitária, conservando-se, ainda que como espectro, uma certa ideia da existência de uma "fala universal", associada aos cânones ou obras clássicas, indefinidamente alvo de releituras e objeto de atenção de artistas e críticos.

Bem, é nesse contexto de uma atriz que participa de processos coletivos ou colaborativos que inicio minha trajetória na dramaturgia, a qual reflete esse processo histórico do acesso da sala de ensaio ao gabinete, não mais encastelado, da produção dramatúrgica. O que significa dizer que meu lugar como dramaturga não é o lugar histórico do dramaturgo cujo texto precede, origina ou mesmo justifica o projeto de montagem, mas, ao contrário, foi somente graças à desconstrução dessas prerrogativas de autor e da democratização da autoria no contexto do teatro de grupo que minha escrita se fez possível. E, apesar de estar num lugar conquistado, esse lugar não é o mesmo lugar em que se encontrava antes o sujeito do "teatro masculino europeu que excetua as tradições populares".

Assim, observo as transformações ocorridas na dramaturgia moderna e na contemporânea a partir de uma perspectiva feminista interseccional ${ }^{3}$, uma vez que o lugar do autor na dramaturgia clássica é sobretudo um lugar masculino e eurocêntrico, não somente por ser historicamente ocupado por homens, mas em especial pela suposição de um discurso "universal", ao passo que meu lugar como autora foi possível a partir do momento em que atrizes puderam participar da autoria de espetáculos, e expressaram, muitas vezes, um "feminist standpoint" ${ }^{4}$ ou "ponto de vista feminista". A emergência da voz feminina na dramaturgia dos grupos de teatro traz não apenas pontos de vista específicos acerca das temáticas abordadas, mas também

\footnotetext{
${ }^{3}$ Grosso modo, o feminismo interseccional, além de trazer uma perspectiva de gênero não-essencialista, enfatiza as interseções entre gênero e contexto social, histórico e político, considerando aspectos étnicos e de classe. De acordo com Butler, uma das teóricas que trazem esta abordagem: "Se alguém 'é' uma mulher, isso certamente não é tudo o que esse alguém é; o termo não logra ser exaustivo, não porque os traços predefinidos de gênero da 'pessoa' transcendam a parafernália específica de seu gênero, mas porque o gênero nem sempre se constituiu de maneira coerente ou consistente nos diferentes contextos históricos, e porque o gênero estabelece interseções com modalidades raciais, classistas, étnicas, sexuais e regionais de identidades discursivamente constituídas. Resulta que se tornou impossível separar a noção de 'gênero' das interseções políticas e culturais em que invariavelmente ela é produzida e mantida." (Butler, 2015, p.21)

${ }^{4}$ Utilizamos aqui como referência para feminist standpoint a conceituação de Djamila Ribeiro (2017) que por sua vez se baseia em Patricia Hill Collins. Ribeiro traz o "ponto de vista feminista" como o fundamento do conceito de lugar de fala. Conforme descrito por Ribeiro, o "ponto de vista feminista" parece se assemelhar bastante ao feminismo interseccional. Collins, porém, enfatiza menos as experiências individuais do que as condições sociais dos grupos nos quais os indivíduos se inserem: "Segundo Collins, a teoria do ponto de vista feminista precisa ser discutida a partir da localização dos grupos nas relações de poder. Seria preciso entender as categorias de raça, gênero, classe e sexualidade como elementos da estrutura social que emergem como dispositivos fundamentais que favorecem as desigualdades e criam grupos em vez de pensar essas categorias como descritivas da identidade aplicada a indivíduos". (Ribeiro, 2017, p.61)
} 
evidencia o universo predominantemente masculino (e eurocêntrico), naturalizado como "universal". De acordo com Djamila Ribeiro (2017, p.69-70:

A teoria do ponto de vista feminista e lugar de fala nos faz refutar uma visão universal de mulher e de negritude, e outras identidades, assim como faz com que homens brancos, que se pensam universais, se racializem, entendam o que significa ser branco como metáfora do poder, como nos ensina Kilomba. Com isso, pretende-se também refutar uma pretensa universalidade. Ao promover uma multiplicidade de vozes o que se quer, acima de tudo, é quebrar com o discurso autorizado e único, que se pretende universal. Busca-se aqui, sobretudo, lutar para romper com o regime de autorização discursiva.

No teatro, a mulher conquista em primeiro lugar a posição de atriz ${ }^{5}$, para a partir dela conquistar espaços - ainda pequenos, mas significativos - na dramaturgia e na direção. Não se trata de uma regra geral para o teatro dito brasileiro, mas aqui voltamos nosso olhar para muitas de nós, mulheres de minha geração, que hoje nos arriscamos na dramaturgia e que chegamos a esse lugar por meio da prática de atuação em processos de criação coletiva ou colaborativa. A título de exemplo, trago o relato de Grace Passô6, acerca de sua experiência com a Cia. Clara no início dos anos 2000, em período anterior à criação do grupo Espanca!?:

[...] do desejo de se ver e ver a nossa realidade representada na cena de uma forma mais explícita, começou uma onda na cidade de dramaturgos, de pessoas que começaram a escrever para teatro. E, normalmente, isso veio de uma demanda da produção, da realidade local. Então eram diretores, atores, atrizes, enfim, que começaram a escrever os textos [...] E nessa Companhia [Clara] que eu entrei, eu pela primeira vez comecei a trabalhar junto com um dramaturgo [Gustavo Naves Franco], tinha uma pessoa que escrevia na sala. Então ele trazia alguns textos, a gente improvisava, ele revia [...] então essa minha relação muito viva e direta e dentro da sala de ensaio com o dramaturgo me fazia muito bem, eu me sentia muito bem, essa possibilidade do cara ver o meu gesto e a partir dele escrever alguma coisa, e de eu poder conversar com ele diretamente, enfim, me aproximou do ato de escrever. [...] então foi aí que eu comecei a trabalhar com textos escritos dentro dos processos. (Passô, 2017)

Também a dramaturga Marina Viana ${ }^{9}$ declara, em entrevista a Joyce Athiê, que a origem de sua escrita se deu a partir de processos coletivos/colaborativos: "Quem

\footnotetext{
${ }^{5}$ Somente a partir do século XVII passou a ser permitido que mulheres atuassem. Até então, no que chamamos "teatro masculino europeu que excetua as tradições populares", os homens interpretavam todos os papéis - inclusive os femininos.

${ }^{6}$ Atriz, diretora e dramaturga mineira. Principais textos: Por Elise (2005), Amores Surdos (2006), Congresso Internacional do Medo (2008), Marcha para Zenturo (2009), Os Ancestrais (2014), Guerrilheiras ou Para a Terra Não Há Desaparecidos (2015), Vaga Carne (2016), Mata Teu Pai (2017), Preto (2018), em coautoria com Marcio Abreu.

${ }^{7}$ Criado em 2004 em Belo Horizonte, o Espanca!, alcança rapidamente projeção nacional, se tornando um importante grupo de teatro brasileiro dos anos 2010. Em sua formação inicial, é composto por Grace Passô, Paulo Azevedo, Marcelo Castro, Gustavo Bones e Samira Ávila, a partir da criação da cena curta Por Elise, que em 2005 se tornou espetáculo. Em 2006, o mesmo coletivo estreia Amores Surdos e em 2008, Congresso Internacional do Medo. Em 2010, numa parceria com o Grupo XIX, de SP, o grupo estreia Marcha para Zenturo, totalizando o quarto espetáculo com dramaturgia de Grace Passô. Também em 2010, o grupo inaugura o Teatro Espanca!, que funciona como sede do grupo e casa de espetáculos, no hipercentro de Belo Horizonte. Em 2012, estreia 0 Líquido Tátil, com texto e direção de Daniel Veronese. Em 2013, Grace Passô deixa o grupo, que estreia em 2014 Dente de leão e em 2015, Real, um programa de quatro peças curtas. 0 mais recente espetáculo é PassAarão, onde se observa uma renovação total do elenco original do grupo.
}

${ }^{8}$ Masterclass com Grace Passô "Biografias da atriz" - Porto Iracema das Artes, 23 de agosto de 2017. 24'20 a 26’50. Disponivel em: https://www.youtube.com/ watch?v=twST-y80910 Acesso em 21 de junho de 2018.

${ }^{9}$ Atriz, diretora e dramaturga mineira. Principais textos: Nossosnuestrosmitos - segundo estudo (2003-2004), criação coletiva com o Mayombe Grupo de Teatro, Elizabeth Está Atrasada (2008) e Sobre Dinossauros, Galinhas e Dragões (2010), criações coletivas com a Primeira Campainha, Festival de Ideias Brutas (2014), À tardinha no ocidente (2014), Calor na Bacurinha, criação coletiva com o Coletivo As Bacurinhas (2015), MPB - Peça Manifesto em Três Estrofes e Um Refrão (2017), e O Anarquista (2017). 
me inspirou foi Sara Rojo. A cada espetáculo, escrevíamos todos juntos. Por isso, não gostava do nome dramaturga. Falava que era uma atriz que escrevia"10. Ao lado de Grace e Marina, tomo-me também como um exemplo possível, entre estas autoras mineiras mais consagradas de minha geração, para pensar o lugar de enunciação da dramaturga que acessa a escrita a partir da sala de ensaio, a partir da posição de atriz, e como essa posição de acesso configura muitas vezes o que chamarei de "dramaturga de si mesma". Parto da análise de minha produção dramatúrgica realizada em Belo Horizonte entre os anos de 2007 e 2015, e de algumas de suas características: a frequência de processos coletivos ou colaborativos, o referenciamento do lugar de enunciação, e a produção baseada na experiência pessoal.

Em meus trabalhos: Por esta porta estar fechada, as outras tiveram que se abrir (2007), do Grupo Mayombe ${ }^{11}$, o texto foi escrito por mim em parceria com Fabiana Amorim, Éder Rodrigues e Fabiane Aguiar, e partimos de uma resposta pessoal do conjunto de atrizes (atores) a uma provocação da direção. Em It (2010), do Grupo Dois Pontos ${ }^{12}$, no qual trabalhei ao mesmo tempo como atriz e dramaturga, a dramaturgia criada por mim e pela atriz Amanda Dias Leite expunha nossas angústias e inquietações acerca da existência, provocadas pela leitura da obra Água Viva, de Clarice Lispector. Já em Encontro com Pedro Juan (2013), do grupo Teatro 17133, outro processo de coautoria, o lugar de enunciação foi explorado numa perspectiva mais biográfica. Tratava-se, nesse espetáculo, de narrar um encontro imaginário entre uma fã (Doce Júnia) e seu ídolo (o escritor cubano Pedro Juan Gutiérrez). Nestes dois últimos trabalhos - It e Encontro com Pedro Juan - a dramaturgia assumiu um caráter performativo ${ }^{14}$, uma vez que estando eu ao mesmo tempo como atriz e dramaturga, me coloquei em cena a partir de uma perspectiva muito pessoal, de

\footnotetext{
${ }^{10}$ Em novembro de 2017, a jornalista Joyce Athiê publicou uma matéria no jornal O Tempo com o seguinte título: "A escrita delas". A matéria pretendia traçar um panorama de dramaturgas mineiras em atividade e reuniu entrevistas com a autora e com as seguintes dramaturgas: Sara Pinheiro, Rita Clemente, Cidinha da Silva, Marina Viana, Silvia Gomez e Grace Passô. Das sete dramaturgas elencadas nessa matéria, à exceção de Cidinha da Silva e Silvia Gomez, todas as outras são atrizes que também, muitas vezes, interpretam seus próprios textos. Fonte: Jornal "O Tempo" - Belo Horizonte/MG. 12 de novembro de 2017. Disponível em: https://www.otempo.com.br/divers\%C3\%A3o/magazine/a-escrita-delas-1.1541714 e https://www.otempo.com.br/divers\%C3\%A3o/magazine/o-que-muda-com-a-presen\%C3\%A7a-da-mulher-na-dramaturgia-1.1541735 Acesso em: 28 maio 2018.
}

${ }^{11}$ Mayombe Grupo de Teatro foi fundado em Belo Horizonte em 1995 e é dirigido há 23 anos por Sara Rojo, artista e professora da Faculdade de Letras da UFMG. Ao longo de sua trajetória de criação, pesquisa e produção artística, o grupo montou os seguintes espetáculos: El Continente Negro (1996), do chileno Marco Antonio de la Parra; Saga Real (1997), da argentina, radicada no Brasil, Graciela Ravetti; Fluxo invertido (1998/1999), de Graciela Ravetti e Denise Pedron; Por um Reino (1999/2000), da argentina Patricia Zangaro; Nossosnuestrosmitos - Primeiro Estudo (2002), Nossosnuestrosmitos - Segundo Estudo (2003/2004) e O julgamento de Don Juan (2005) - trilogia mítica com criação coletiva do grupo; Por esta porta estar fechada, as outras tiveram que se abrir (2007), obra criada pela autora em conjunto com Éder Rodrigues, Fabiana Amorim e Fabiane Aguiar; A Pequenina América e sua Avó \$ifrada de escrúpulos (2010), de Éder Rodrigues, Marcos Coletta e Marina Viana; Klássico (com k) (2013), de Didi Vilella, Éder Rodrigues, Fernando de Oliveira, Flávia Almeida e Marina Viana; Amor: Manifesto antiacademicista pró-bruxaria sem rigor conceitual do meu lado ocidental que Euripedes desconhece (2015), solo concebido por Marina Viana; A mulher que andava em círculos (2016) e Happy hour (2017), ambos escritos por Éder Rodrigues.

${ }^{12}$ Grupo Dois Pontos foi um coletivo criado em Belo Horizonte pela autora, em conjunto com as(o) artistas Amanda Dias Leite, Marina Viana e Geraldo Octaviano. O grupo manteve atividades entre 2009 e 2013, e produziu o espetáculo It (2010), com direção de Marina Viana, e a cena curta Freaking People (2013), com direção de Dayse Belico.

${ }^{13}$ Teatro 171 é um coletivo fundado em Belo Horizonte por Henrique Limadre, Cléo Magalhães, Fabiana Bergamini, Gabriel Castro, Marina Viana, Javier Galindo e Patrícia Diniz, a partir da montagem de Quando o Peixe Salta, espetáculo dirigido por Rodrigo Campos e resultado do OFICINÃO 2006, projeto de capacitação de atores do Galpão Cine Horto. O Teatro 171 mantém desde 2007 sede na rua Capitão Bragança, no bairro Horto, onde ocorrem ensaios, espetáculos, além de realizar festas e eventos como forma de manutenção do espaço, tais como: "Buteco 171", "Bingay" e "Maldição de João Ceschiatti". A partir de 2016, o grupo mantém um projeto chamado "Varejão", espécie de cabaré de variedades capitaneado pela atriz Marina Viana e que une as festas e eventos já tradicionais do grupo, com o aspecto do fomento à criação artística. São espetáculos do grupo: Av. Pindorama, 171 (2009), Drika (2011), Encontro com Pedro Juan (2013), Simplesmente Marta (2015) e Territórios (2016), todos com direção de Henrique Limadre.

${ }^{14}$ Entendido aqui a partir do conceito de "encenação performativa" defendido por Antonio Araújo: "o caráter autobiográfico, não-representacional e não-narrativo, de contraponto à ilusão, e baseado na intensificação da presença e do momento da ação, num acontecimento compartilhado entre artistas e espectadores - traços característicos da arte performática - vão orientar as sugeridas aproximações com o campo teatral". (Araújo, 2008, p.253) 
forma que as fronteiras entre arte e vida foram borradas, e em ambos os trabalhos me vi em diversos momentos "representando a mim mesma" em cena. No caso de Encontro com Pedro Juan isso se deu de maneira radical, uma vez que Doce Júnia ser representada por mim criava uma ambiguidade na qual se ancorava o texto dramatúrgico.

Em Vendaval (2014) e Anemia (2015), minhas últimas produções, a escrita não foi feita junto ao processo de montagem, caracterizando processos de criação dramatúrgica "de gabinete". E coloco entre aspas porque ambos os processos envolveram redes de relações criativas com outras(os) artistas, sem as quais os trabalhos não teriam existido. Em Vendaval, escrito em parceria com Glauce Guima, partimos de uma situação parodiada do contexto de nossa relação de amizade: uma amiga sai de Minas Gerais e vai visitar a outra no Rio de Janeiro, e a partir desse mote os temas da morte, da velhice e a relação com o tempo e o dinheiro foram surgindo. $O$ resultado final trouxe uma situação ficcional e, em certa medida, fantástica, com personagens mais velhas, com experiências muito diferentes das nossas. Entretanto, o ponto de partida ainda foi o das nossas memórias e experiências pessoais. Já Anemia surgiu a partir de uma experiência de escrita compartilhada - um Ateliê de Dramaturgia ${ }^{15}$ - e foi finalizado de forma individual. Nesse texto, minhas memórias relacionadas à vivência na cidade de Congonhas, Minas Gerais, foram elementos estruturantes para tematizar a relação entre moradores de uma cidade pequena e uma grande empresa da área de mineração. Trata-se também de uma obra de ficção, porém erigida a partir de fontes autobiográficas, e num diálogo com as(os) artistas participantes do Ateliê.

Tais experiências traçaram as bases da minha escrita até o presente momento: seja em processos coletivos em sala de ensaio, seja na escrita também compartilhada, porém sem o suporte de experimentações práticas, o ponto de partida sempre foi a experiência pessoal e coletiva (da dramaturga, da dramaturga/atriz ou do coletivo de artistas), seja em forma de memória ou autobiografia, resposta pessoal a um tema ou paródia de uma situação real. A partir dessa análise, arrisco dizer que me construí até esse momento, ainda que não de forma propositada, como uma "dramaturga de si mesma".

Olhando para o cenário no qual foram produzidos estes trabalhos, é possível perceber que tal "dramaturgia de si mesma" faz parte de um contexto em que procedimentos de criação teatral embasados numa certa pessoalidade dos(as) artistas fizeram parte do tempo/espaço de toda uma geração de artistas e grupos que se formou e trabalhou em Belo Horizonte no período em que lá vivi (2001-2015). Como exemplo, trago o relato de Grace Passô (2017), e de como suas memórias e experiências pessoais foram a base para a criação de Por Elise:

[...] eu fui reunindo um pouco coisas que fizeram parte da minha vida mesmo - eu passei um trauma horrendo na minha vida, quando criança eu perdi um cachorro que morreu, e eu fiquei muito louca com isso [...] a minha mãe é baiana e uma contadora de histórias, ela fala, ela conta histórias, e ela tem um quintal [...] um dos únicos pés que eu plantei ali com ela naquele quintal que ela ama foi

\footnotetext{
${ }^{15}$ Ateliês de Dramaturgia são espaços coletivos de formação em dramaturgia inspirados nas oficinas de escrita dramática francesas (tais como as de Jean-Pierre Sarrazac). Entre outras experiências brasileiras, em São Paulo Adélia Nicolete sistematizou seu trabalho com os ateliês num diálogo com as artes visuais em sua tese defendida na USP em 2013, e em Belo Horizonte os atores e dramaturgos Vinícius Souza e Assis Benevenuto vêm conduzindo atividades nesse formato a partir desse mesmo ano. Em 2014, o Núcleo de Pesquisa em Dramaturgia do Galpão Cine Horto acolheu a proposta desses artistas, da qual participei com o projeto de escrita de Anemia, que ganhou corpo a partir dos encontros semanais do Ateliê, entre agosto e dezembro de 2014 , nas tardes de segunda-feira, das $15 \mathrm{~h}$ às $18 \mathrm{~h}$.
} 
um pé de abacate [...] fui agregando nessa história coisas que me chamavam a atenção, sempre me chamou muito a atenção os lixeiros da cidade de $\mathrm{BH}$, sempre achei muito excitante [...] e na verdade o que eu fiz foi reunir um pouco essas lembranças, essas memórias, e também junto com ficções criadas para articular uma narrativa. (Passô, 2017) $)^{16}$

Passô relaciona a busca em fontes pessoais na criação dramatúrgica sobretudo a um desejo das(os) artistas por representatividade, diante de uma cena muitas vezes construída a partir do predomínio de modelos eurocêntricos. Em nossa visão, além desse aspecto, nem sempre consciente a todas(os) os(as) artistas que trabalham dessa forma, é fator preponderante a participação em processos coletivos/colaborativos, cujos procedimentos metodológicos levam à exploração da subjetividade.

Com uma tradição de teatro de grupo e de criação em grupo a partir dos anos de 1980, a capital mineira absorve, no início dos anos 2000, o pensamento de criação colaborativa, a partir, principalmente, da atuação do Galpão Cine Horto - Centro Cultural do Grupo Galpão, e de sua parceria com o dramaturgo paulista Luís Alberto de Abreu, que coordena já em 1999 o primeiro Núcleo de Dramaturgia do Galpão Cine Horto. Em 2000, Luis Alberto de Abreu é responsável pela dramaturgia de: Um trem chamado desejo, do Grupo Galpão, e em 2003 orienta o Projeto Cena 3x4, promovido pelo Galpão Cine Horto. O Cena 3x4 propôs uma investigação da metodologia de criação colaborativa e contou com a participação de grupos mineiros como Luna Lunera, Trama, Maldita, Acômica, Invertido, entre outros.

Dessa maneira, a disseminação dessa metodologia de trabalho se multiplicou entre diferentes grupos e artistas de Belo Horizonte e impactou de forma ampla a produção dos anos subsequentes na capital. Rita Maia é uma das artistas que participou do Projeto Cena $3 \times 4$. Seu grupo, Teatro Invertido, adotou a metodologia em seus trabalhos subsequentes e sua dissertação de mestrado reflete sobre as fontes de criação do ator no processo colaborativo. De acordo com ela, na ausência de um texto dramatúrgico prévio ou da concepção prévia da direção, o ator traz como material para a cena suas próprias experiências pessoais:

O ator, então, no seu processo de criação, parte inicialmente de si mesmo, dos seus desejos, das suas vivências, da sua maneira de enxergar a temática que vai ser trabalhada no espetáculo. Ele vai em busca de um resgate de sua memória pessoal, não só a memória vivida, mas também a ficcional - todos os livros, filmes e músicas que fizeram parte significativa de sua vida.

Todo ator trabalha segundo a sua própria perspectiva, mesmo criando um personagem que já existe previamente. No entanto, no processo colaborativo, ele dá o pontapé na criação a partir de si mesmo e da sua memória e esse procedimento vai ser decisivo na criação desse personagem, e do espetáculo que ainda se formará (em processo). (Maia, 2010, p.42-43)

Apesar de não ter participado do Projeto $3 \times 4$ e de os meus processos criativos, rememorados acima, não se constituírem como criações colaborativas stricto sensu, avalio que vivendo e trabalhando como atriz e também como dramaturga neste mesmo espaço/tempo, eu também fiz parte de um certo movimento artístico mineiro com

\footnotetext{
${ }^{16}$ Masterclass com Grace Passô "Biografias da atriz" - Porto Iracema das Artes, 23 de agosto de 2017. 1h18 a 1h23. Disponível em: https://www.youtube.com/ watch?v=twST-y80910 Acesso em 21 de junho de 2018.
} 
o processo colaborativo e assimilei um procedimento de criação no qual a subjetividade dos(as) artistas envolvidos(as) tem grande importância na criação, uma vez que este elemento é comum em todas as minhas criações dramatúrgicas e de coletivos de artistas meus(minhas) contemporâneos(as), tais como: Cia Primeira Campainha, Grupo Espanca!, Cia Luna Lunera, Teatro 171, ZAP18, Grupo Teatro Invertido, entre outros(as).

Refletindo sobre essa característica da pessoalidade de atrizes (atores)/dramaturgas(os) constituir-se como um elemento de destaque em processos coletivos/ colaborativos de Belo Horizonte no início do século XXI, surge o questionamento: até que ponto esse reforço no aspecto de subjetividade das(os) artistas na criação reforça a dicotomia entre "particular" e "universal", democratizando a autoria da cena contemporânea em suas expressões particulares, mas ainda reservando o título de "universal" como categoria mítica no imaginário teatral? Até que ponto o acesso de atrizes (atores), pela sala de ensaio, ao campo da dramaturgia, é requisitado e legitimado apenas no lugar da exploração autobiográfica, restringindo assim o alcance de suas proposições artísticas?

De acordo com uma conhecida máxima feminista, "o pessoal é político". Ora, uma dramaturgia feminista ou vista a partir de um ponto de vista feminista, necessita então quebrar as fronteiras que ainda separam o público do privado, e reconhecer no lugar de enunciação pessoal das(os) artistas os aspectos sociais, políticos, e também - por que não? - universais que integram suas obras.

\section{Referências}

ARAÚJO, Antônio. A Encenação Performativa. Revista Sala Preta. São Paulo: Escola de Comunicação e Artes. n. 8, p. 253-258, 2008.

BEAUVOIR, Simone de. O segundo sexo. Volume 1: Fatos e Mitos. 4a edição. Tradução de Sérgio Milliet. São Paulo: Difusão Europeia do Livro, 1970.

BOAL, Augusto. Teatro do Oprimido e outras poéticas políticas. 6a edição. Rio de Janeiro: Civilização Brasileira, 1991.

BRANDÃO, Tania. As Companhias Teatrais Modernas. In: FARIA, João Roberto (dir.); J. Guinsburg e João Roberto Faria (projeto e planejamento editorial) História do Teatro Brasileiro, volume 2: do modernismo às tendências contemporâneas. São Paulo: Perspectiva: Edições SESCSP, 2013.

BRECHT, Bertolt. Um homem é um homem. In: Teatro Completo, v. 2, Rio de Janeiro: Paz e Terra, 1987.

BUTLER, Judith. Problemas de Gênero: Feminismo e subversão da identidade. Rio de Janeiro: Civilização Brasileira, 2015. 
CALVINO, Ítalo. Por que ler os clássicos. Tradução de Nilson Moulin. $2^{\underline{a}}$ edição. São Paulo: Companhia das Letras, 1993.

CASÉ, Regina. Entrevista para o documentário Xarabovalha! de Heloísa Buarque de Holanda, 1978. Disponível em: https://www.youtube.com/watch?v=Se1-6p-Pu_A Acesso em: 24 maio 018.

MAIA, Rita de Cássia Pinho. O Ator em Questão: Um foco na função do ator no Processo Colaborativo do Grupo Teatro Invertido. Belo Horizonte, 2010. Dissertação (Mestrado) - Escola de Belas Artes, Universidade Federal de Minas Gerais - UFMG.

PAVIS, Patrice. Dicionário de teatro. São Paulo: Perspectiva, 2005.

RIBEIRO, Djamila. O que é lugar de fala? Belo Horizonte: Letramento, 2017.

SZONDI, Peter. Teoria do Drama Moderno (1880-1950). Tradução: Luiz Sérgio Repa. São Paulo: Cosac \& Naify, 2001.

VINCENZO, Elza Cunha. Um teatro da mulher: dramaturgia feminina no palco brasileiro contemporâneo. São Paulo: Perspectiva, 1992.

Recebido em: 30/09/2018

Aprovado em: 04/11/2018 